\title{
The effect of dietary starch level on postprandial glucose and insulin concentrations in cats and dogs
}

\author{
Adrian K. Hewson-Hughes*, Matthew S. Gilham, Sarah Upton, Alison Colyer, Richard Butterwick \\ and Andrew T. Miller \\ Waltham Centre for Pet Nutrition, Waltham-on-the-Wolds, Melton Mowbray, Leicestershire LE14 4RT, UK
}

(Received 15 October 2010 - Revised 8 February 2011 - Accepted 13 February 2011)

\section{Abstract}

A charge made against feeding dry foods to cats is that the high carbohydrate (i.e. starch) content results in high blood glucose levels which over time may have detrimental health effects. The present study determined the post-meal concentrations of plasma glucose and insulin in adult cats (seven males and four females) and dogs (Labrador retrievers; four males and five females) fed dry diets with low-starch (LS), moderate-starch (MS) or high-starch (HS) levels. In a cross-over design with at least $7 \mathrm{~d}$ between the test meals, plasma glucose and insulin concentrations were measured following a single meal of a LS, MS and HS diet ( $209 \mathrm{~kJ} / \mathrm{kg}$ bodyweight). Only the HS diet resulted in significant post-meal increases in plasma glucose concentration in cats and dogs although the time-course profiles were different between the species. In cats, plasma glucose concentration was significantly increased above the pre-meal concentration from $11 \mathrm{~h}$ until $19 \mathrm{~h}$ after the meal, while in dogs, a significant increase above baseline was seen only at the $7 \mathrm{~h}$ time point. Plasma insulin was significantly elevated in dogs $4-8 \mathrm{~h}$ following the MS diet and $2-8 \mathrm{~h}$ after the HS diet. In cats, plasma insulin was significantly greater than baseline from 3-7 and $11-17 \mathrm{~h}$ after the HS diet. The time lag (approximately $11 \mathrm{~h}$ ) between eating the HS diet and the subsequent prolonged elevation of plasma glucose concentration seen in cats may reflect metabolic adaptations that result in a slower digestive and absorptive capacity for complex carbohydrate.

\section{Key words: Feline: Canine: Glycaemia: Insulinaemia: Carbohydrate}

Having evolved as a carnivore consuming a diet naturally high in animal protein and low in carbohydrate has contributed to the belief that feeding carbohydrates to cats (particularly through dry commercial pet foods in which the carbohydrate source is predominantly starch) is detrimental to the cat's health and may play a role in the pathogenesis of a number of feline disorders, most notably type 2 diabetes mellitus (DM). The mechanisms suggested to underlie the development of DM in cats fed high-carbohydrate diets include direct 'glucotoxic' effects (e.g. apoptosis of pancreatic $\beta$-cells) and gradual 'burnout' of pancreatic $\beta$-cells due to prolonged stimulation and insulin secretion in response to elevated plasma glucose concentration ${ }^{(1)}$

The carbohydrate content of manufactured dry cat foods varies widely, typically contributing between 25 and $50 \%$ of the metabolisable energy of the diet, although, recently, dry diets with a carbohydrate content of 10-15\% metabolisable energy have appeared on the market. The aim of the present study was to determine the post-meal profiles of plasma glucose and insulin concentrations in cats following a meal of a low-starch (LS) diet, a moderate-starch (MS) diet and a high-starch (HS) diet. A secondary aim was to carry out a species comparison of the glucose and insulin response to the same diets in dogs. Dogs also belong to the mammalian order Carnivora (but are not obligate carnivores like the cat) and so the species comparison was to give some insight into metabolic differences/similarities between these species in response to food intake.

\section{Methods}

\section{Animals}

A total of eleven neutered adult male $(n 7)$ and female $(n$ 4) domestic shorthair cats and nine adult Labrador retriever dogs ( $n$ 4, male, neutered; $n$ 3, female, neutered; $n 2$, female, entire) were studied. The cats were housed individually in environmentally enriched lodges and socialised for several hours each day, except for the test-meal day. Before the test-meal day, dogs were housed in pairs, allowed several hours paddock exercise and walked on-lead each day; on the test-meal day, dogs were individually housed and given

Abbreviations: DM, diabetes mellitus; HS, high starch; LS, low starch; MS, moderate starch.

*Corresponding author: Dr A. K. Hewson-Hughes, fax +44 1664 415440, email adrian.hewson-hughes@effem.com 
calm social interaction but no exercise. All animals underwent habituation programmes to accustom them to the blood sampling procedures to be carried out on the test-meal day. The experimental procedures were approved by the Waltham Ethical Review Committee and performed in accordance with UK Home Office legislation.

\section{Diets}

For the study, three dry diets were manufactured at Mars Petcare (Verden, Germany) and nutrient profiles (see Table 1) were analysed at Eurofins Laboratories Limited (Wolverhampton, UK). The carbohydrate (starch) source was the same for all three diets (whole maize), but at different inclusion levels. Total sugars (e.g. glucose, sucrose, fructose, galactose, lactose and maltose) constituted $<1.0 \mathrm{~g} / 100 \mathrm{~g}$ of each diet (as fed). Between test-meal days, cats were fed Whiskas ${ }^{\circledR}$ complete dry diet and dogs were fed Pedigree ${ }^{\circledR}$ complete dry diet.

\section{Experimental procedures}

Following an overnight (24h) fast, animals were weighed (to calculate how much test meal to offer) and a cannula inserted into a cephalic vein. For the dog study, blood samples $(1.3 \mathrm{ml})$ were collected 120 and $30 \mathrm{~min}$ before the test meal and then at $1,2,3,4,5,6,7,8,9$ and $10 \mathrm{~h}$ after the start of the test meal. For cats, blood samples $(1.0 \mathrm{ml})$ were collected $1 \mathrm{~h}$ before and $3,5,7,9,11,13,15,17$ and $19 \mathrm{~h}$ after the start of the meal. Each meal was consumed within 10 min of being offered by both dogs and cats.

Blood was collected into EDTA and sodium fluoridepotassium oxalate (Flu-Ox) tubes and kept on ice until centrifugation (within $30 \mathrm{~min}$ of collection) at $2000 \boldsymbol{g}$ for $10 \mathrm{~min}$ at $4^{\circ} \mathrm{C}$. EDTA plasma was stored at $-80^{\circ} \mathrm{C}$ until insulin concentration was determined by RIA - for cats, the porcine insulin kit (PI-12K; Millipore (UK) Limited, Watford, Herts, UK) was used and for dogs, the human insulin kit (DSL1600; Diagnostic System Laboratories, Inc., Webster, TX, USA; Beckman Coulter (UK) Limited, High Wycombe, Bucks, UK) was used. Plasma from Flu-Ox tubes was assayed immediately for glucose using an automated analyser (AU400; Beckman Coulter (UK) Limited High Wycombe, Bucks, UK). Cannula patency was maintained by flushing with $0.5 \mathrm{ml}$ of heparinised saline $(100 \mathrm{IU} / \mathrm{ml}$ heparin in $0.9 \%$ saline) after each sample. Before collecting the samples, $0.3 \mathrm{ml}$ of blood was withdrawn and discarded to avoid any dilution of the analytes of interest by saline in the cannula.

\section{Statistical analysis}

Response profiles were analysed (Statgraphics Centurion, version XV; Statpoint Technologies, Inc., Warrenton, VA, USA) using a mixed model analysis to allow for repeated measures over time; diet, time and their interaction were included as fixed effects. Graphs of response profiles are presented with least significant difference intervals (adjusted accordingly to account for multiple comparisons to maintain the overall significance level at 5\%) for comparisons over time within a diet (i.e. to see changes from baseline for each diet). Means can be interpreted as being significantly different at the $5 \%$ level if these intervals do not overlap.

\section{Results}

\section{Cats}

No significant difference from pre-meal glucose concentration was seen in cats at any time point following ingestion of the MS diet, while plasma glucose concentration was significantly lower than the pre-meal concentration from 3 to $7 \mathrm{~h}$ following ingestion of the LS diet (Fig. 1(a)). Following the HS diet, plasma glucose was significantly elevated compared with the pre-meal concentration from $11 \mathrm{~h}$ and remained significantly elevated thereafter (Fig. 1(a)). Postprandial insulin concentration was not significantly different at any time point compared with the pre-meal concentration in cats fed the LS and MS diets, while ingestion of the HS diet was associated with significantly elevated insulin concentration from $3-7$ and $11-17 \mathrm{~h}$ after the meal (Fig. 1(b)).

Table 1. Macronutrient composition of the three diets (as fed)

\begin{tabular}{|c|c|c|c|}
\hline Nutrient $(\mathrm{g} / 100 \mathrm{~g})$ & Low-starch diet & Medium-starch diet & High-starch diet \\
\hline Moisture & $8 \cdot 0$ & 7.5 & $7 \cdot 3$ \\
\hline Protein & $51 \cdot 3$ & $37 \cdot 6$ & 29.5 \\
\hline EE & $18 \cdot 9$ & $15 \cdot 5$ & $11 \cdot 0$ \\
\hline CF & 2.9 & 1.4 & $3 \cdot 4$ \\
\hline Ash & $6 \cdot 6$ & $7 \cdot 0$ & $7 \cdot 4$ \\
\hline $\mathrm{NFE}^{\star}$ & $12 \cdot 3$ & $31 \cdot 0$ & 41.4 \\
\hline Total dietary fibre & $4 \cdot 1$ & $5 \cdot 0$ & $6 \cdot 5$ \\
\hline Total starch & 9.5 & $23 \cdot 0$ & $31 \cdot 7$ \\
\hline Gelatinised starch & 8.9 & $21 \cdot 6$ & 29.4 \\
\hline Starch gelatinisation (\%) & 93.7 & 93.9 & $92 \cdot 7$ \\
\hline Metabolisable energy $(\mathrm{MJ} / \mathrm{kg}) \dagger$ & $17 \cdot 7$ & $17 \cdot 3$ & $16 \cdot 0$ \\
\hline Protein:energy ratio (\%)‡ & $48 \cdot 3$ & $36 \cdot 3$ & $30 \cdot 8$ \\
\hline Fat:energy ratio $(\%) \ddagger$ & $40 \cdot 1$ & $33 \cdot 7$ & $25 \cdot 9$ \\
\hline Carbohydrate:energy ratio (\%)‡ & 11.6 & $30 \cdot 0$ & $43 \cdot 3$ \\
\hline
\end{tabular}

$\mathrm{EE}$, ether extract (fat); $\mathrm{CF}$, crude fibre; NFE, nitrogen-free extract.

${ }^{*} \mathrm{NFE}=100-(\mathrm{M}+\mathrm{P}+\mathrm{EE}+\mathrm{CF}+\mathrm{A})$, where $\mathrm{M}$ refers to moisture, $\mathrm{P}$ is protein and $\mathrm{A}$ is ash

$\dagger$ Metabolisable energy $(\mathrm{MJ} / \mathrm{kg}$ diet $)=0.1672 \times(\mathrm{P}+\mathrm{NFE})+0.3762 \times \mathrm{EE}$.

$\ddagger(100 \times \mathrm{g}$ nutrient $\times \alpha)$ /metabolisable energy, where $\alpha=0.1672$ for $\mathrm{P}$ and NFE and 0.3762 for EE. 

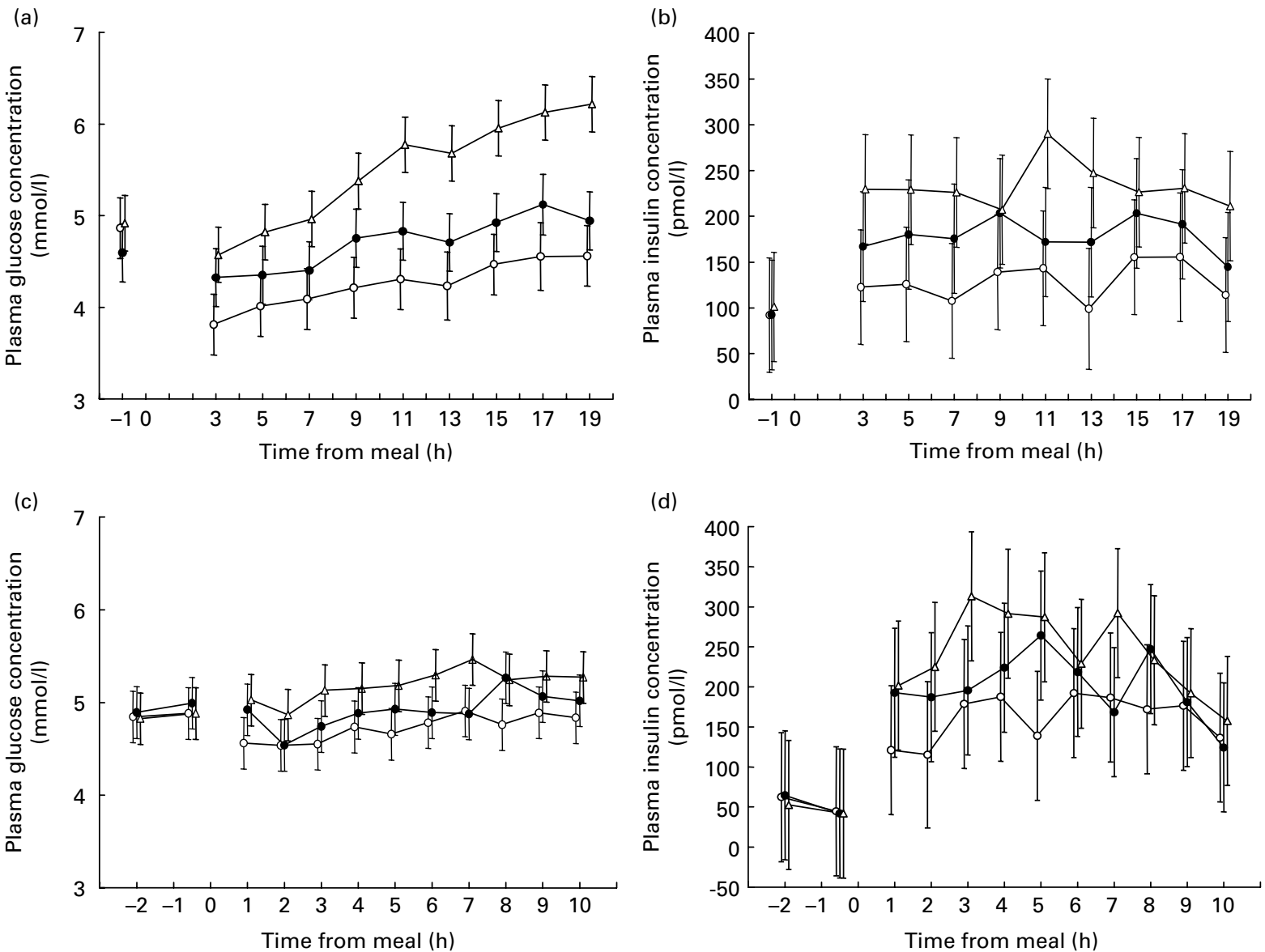

Fig. 1. Values are means with $\pm 95 \%$ least significant difference intervals represented by vertical bars. (a and $c)$ Plasma glucose and (b and d) insulin concentration in $(a$ and $b)$ eleven cats and $(c$ and d) nine dogs before and following a meal $(209 \mathrm{~kJ} / \mathrm{kg}$ bodyweight at time $=0)$ of a low $(O)$, moderate $(\bullet)$ and high $(\triangle)$ starch diet.

\section{Dogs}

There was no significant difference in pre-meal baseline values for glucose and insulin between the diets (at -2 and $-0.5 \mathrm{~h}$ ). All time-effect comparisons were made to baseline at $-0.5 \mathrm{~h}$. Minimal changes in plasma glucose concentration compared with the pre-meal concentration were observed following any of the three diets - the only statistically significant change was an increase at $7 \mathrm{~h}$ after the HS diet compared with the pre-meal concentration (Fig. 1(c)). Following the HS diet, plasma insulin concentration in dogs was significantly higher than pre-meal values from 2 to $8 \mathrm{~h}$ post-meal (Fig. 1(d)). Following the MS diet, insulin was significantly greater than pre-meal values at 4, 5, 6 and $8 \mathrm{~h}$, while insulin was never significantly different from pre-meal values following the LS diet (Fig. 1(d)).

\section{Discussion}

The present study has determined the postprandial concentrations of glucose and insulin in lean (i.e. not overweight), healthy cats and dogs fed dry diets with different carbohydrate levels, reflective of commercially available dry cat food products. The results show differences in the time-course profiles of glucose and insulin concentrations between cats and dogs and reflect the differences in carbohydrate metabolism between these species.

The relatively long time (approximately $11 \mathrm{~h}$ ) for blood glucose levels to become significantly higher than the pre-meal concentration in cats following the HS diet may reflect decreased activities of starch-digesting enzymes - i.e. a lack of salivary amylase and low pancreatic amylase activity in this species compared with $\operatorname{dogs}{ }^{(2)}$. This is somewhat later than reported in other studies in cats where significant increases in plasma glucose concentration were observed as early as $4 \mathrm{~h}$ after eating ${ }^{(3-5)}$. Interestingly, while a statistically significant increase in plasma glucose concentration was seen at $4 \mathrm{~h}$ in these studies, Appleton et al. ${ }^{(4)}$ reported that the modal time for peak glucose concentration was $10 \mathrm{~h}$ following a rice-based dry diet and $18 \mathrm{~h}$ for a sorghum-based diet, which is in keeping with the idea that the processes of starch digestion and subsequent glucose absorption occur gradually in cats over a relatively long period. The apparent lack of change in plasma glucose concentration seen in dogs may be due to changes occurring before the earliest sampling point $(<1 \mathrm{~h}$ after the meal). Indeed, other studies have found that the glucose peak following various dry diets frequently occurred $<1 \mathrm{~h}$ following the meal ${ }^{(6,7)}$. However, the present 
results do provide new information on the time course of post prandial glucose and insulin concentrations in dogs, given that a significant increase in plasma glucose was seen $7 \mathrm{~h}$ after the HS diet and the plasma insulin concentration was significantly elevated from 2 to $8 \mathrm{~h}$ after the HS diet and from 4 to $8 \mathrm{~h}$ after the MS diet.

The time for plasma glucose concentration to return to baseline values in cats ranges from 8 to $18 \mathrm{~h}$ following a meal $^{(3,4,8)}$. In the present study, however, plasma glucose concentration was still significantly higher than the pre-meal concentration at $19 \mathrm{~h}$ after the HS meal, and therefore it was not possible to determine the maximal increase or the time for plasma glucose to return to baseline levels. The time for plasma glucose concentration to return to baseline is also variable in dogs, although it is typically quicker than for cats, e.g. $3-5 \mathrm{~h}$ following a meal ${ }^{(6,7)}$. The reason for these differences probably reflects the lack of glucokinase (low affinity but high capacity for glucose) and presence of hexokinase (high affinity but low capacity) in feline tissues, while canine tissues express both enzymes ${ }^{(9,10)}$. Since the cat's natural diet would be low in carbohydrate, it is perhaps not surprising that systems for the digestion, absorption and metabolism of carbohydrate are somewhat less active in this species. It is possible that slower digestion of carbohydrate may prevent high blood glucose levels occurring in the cat following a meal high in complex carbohydrate by providing glucose at a rate that can be metabolised by the low-capacity hexokinase enzyme.

A charge made against feeding dry foods to cats is that the high carbohydrate content results in hyperglycaemia which may over time lead to detrimental effects on pancreatic $\beta$-cell function and eventually to type $2 \mathrm{DM}$. Chronic hyperglycaemia induced by intravenous infusion of glucose has been shown to impair insulin secretion, decrease $\beta$-cell number and induce diabetic ketosis in cats ${ }^{(11,12)}$, although at a plasma glucose concentration (approximately $30 \mathrm{mmol} / \mathrm{l}$ ) that would be seen in uncontrolled diabetes and not a physiological situation such as following food intake. The International Diabetes Federation defines post-meal hyperglycaemia in humans as a plasma glucose concentration of $>7.8 \mathrm{mmol} / 12 \mathrm{~h}$ after ingestion of food ${ }^{(13)}$. In the present study, only the HS diet produced a significant postprandial rise in plasma glucose concentration in cats and the highest concentration recorded was $6.9 \mathrm{mmol} / \mathrm{l}$, which is lower than the value used to define hyperglycaemia for humans. The present study suggests that feeding high-carbohydrate diets to cats does not lead to glucose levels previously shown to induce $\beta$-cell dysfunction and diabetic symptoms in cats $^{(11,12)}$. Other studies in cats have failed to show a detrimental effect of high dietary carbohydrate intake on insulin sensitivity or $\beta$-cell function ${ }^{(14-16)}$. Furthermore, if postprandial hyperglycaemia resulting from dietary carbohydrate intake was an important risk factor for the development of feline DM, then an increased incidence of DM might be expected among cats fed on dry diets (since these are typically higher in carbohydrate than wet diets) and evidence from two recent epidemiological studies indicates that this is not the case $e^{(17,18)}$
In summary, postprandial glucose and insulin profiles were strikingly similar in cats and dogs following intake of the LS and MS dry diets. In contrast, the responses of cats were different from dogs following the HS diet, which most probably reflects known metabolic adaptations of cats that result in slower digestion of starch and slower uptake of glucose from the blood. The present study shows that plasma glucose concentrations can remain statistically significantly higher than pre-meal concentrations in cats for at least $8 \mathrm{~h}$ following intake of a HS diet. However, there are no known adverse effects of this level of hyperglycaemia in cats.

\section{Acknowledgements}

The authors have no conflicts of interest to declare. The present study was funded by Mars Petcare. A. K. H.-H. and A. T. M. conceived and designed the study. A. K. H.-H., M. S. G., S. U. and A. T. M. carried out the research and A. C. carried out the statistical analysis. A. K. H.-H. wrote the manuscript with critical input and guidance from R. B. The authors would like to thank many individuals at the Waltham Centre for Pet Nutrition for their skills and expertise in the training, welfare and sampling of cats and dogs used in the study.

\section{References}

1. Rand JS, Fleeman LM, Farrow HA, et al. (2004) Canine and feline diabetes mellitus: nature or nurture? J Nutr 134, 2072S-2080S.

2. Meyer H \& Kienzle E (1991) Dietary protein and carbohydrates: relationship to clinical disease. Proc Purina Int Nutr Symp 13-26.

3. Appleton DJ, Rand JS \& Sunvold GD (2001) Insulin sensitivity decreases with obesity, and lean cats with low insulin sensitivity are at greatest risk of glucose intolerance with weight gain. J Feline Med Surg 3, 211-228.

4. Appleton DJ, Rand JS, Priest J, et al. (2004) Dietary carbohydrate source affects glucose concentrations, insulin secretion and food intake in overweight cats. Nutr Res $\mathbf{2 4}$, 447-467.

5. de-Oliveira LD, Carciofi AC, Oliveira MCC, et al. (2008) Effects of six carbohydrate sources on diet digestibility and postprandial glucose and insulin responses in cats. J Anim Sci 86, 2237-2246.

6. Nguyen P, Dumon H, Buttin P, et al. (1994) Composition of meal influences changes in postprandial incremental glucose and insulin in healthy dogs. J Nutr 124, 2707S-2711S

7. Carciofi AC, Takakura FS, de-Oliveira LD, et al. (2008) Effects of six carbohydrate sources on dog diet digestibility and post-prandial glucose and insulin response. J Anim Physiol Anim Nutr 92, 326-336.

8. Bouchard GF \& Sunvold GD (2000) Effect of dietary carbohydrate source on postprandial plasma glucose and insulin concentration in cats. In Recent Advances in Canine and Feline Nutrition, Iams Nutrition Symposium Proceedings, vol. III, pp. 91-101 [GA Reinhart and DP Carey, editors]. Wilmington, $\mathrm{OH}$ : Orange Frazer Press.

9. Ballard FJ (1965) Glucose utilization in mammalian liver. Comp Biochem Physiol 14, 437-443.

10. Tanaka A, Inoue A, Takeguchi A, et al. (2005) Comparison of expression of glucokinase gene and activities of enzymes 
related to glucose metabolism in livers between dog and cat. Vet Res Commun 29, 477-485.

11. Link KRJ \& Rand JS (1996) Glucose toxicity in cats. J Vet Intern Med 10, 185.

12. Zini E, Osto M, Franchini M, et al. (2008) Hyperglycaemia but not hyperlipidaemia causes beta cell dysfunction and beta cell loss in the domestic cat. Diabetologia 52, 336-346.

13. Ceriello A \& Colagiuri S (2008) International diabetes federation guideline for management of postmeal glucose: a review of recommendations. Diabet Med 25, 1151-1156.

14. Thiess S, Becskei C, Tomsa K, et al. (2004) Effects of high carbohydrate and high fat diet on plasma metabolite levels and on i.v. glucose tolerance test in intact and neutered male cats. J Feline Med Surg 6, 207-218.

15. Hoenig M, Thomaseth K, Waldron $M$, et al. (2007) Insulin sensitivity, fat distribution, and adipocytokine response to different diets in lean and obese cats before and after weight loss. Am J Physiol Regul Integr Comp Physiol 292, $\mathrm{R} 227-\mathrm{R} 234$.

16. Slingerland LI, van Haeften TW \& Beynen AC, et al. (2008) Effects of dietary macronutrients on glucose disposal, $\beta$-cell function, insulin sensitivity, arterial blood pressure and body composition in healthy weight cats fed for weight stasis. PhD Thesis (Risk factors for feline diabetes mellitus), Utrecht University.

17. Slingerland LI, Fazilova VV, Plantinga EA, et al. (2009) Indoor confinement and physical inactivity rather than the proportion of dry food are risk factors in the development of feline type 2 diabetes mellitus. Vet J 179, 247-253.

18. McCann TM, Simpson KE, Shaw DJ, et al. (2007) Feline diabetes mellitus in the UK: the prevalence within an insured cat population and a questionnaire-based putative risk factor analysis. J Feline Med Surg 9, 289-299. 